\title{
O Antropoceno como Regime de Historicidade
}

\author{
The Anthropocene as a Regime of Historicity
}

\author{
Alfredo Ricardo Silva Lopes* \\ Mário Martins Viana Junior**
}

Resumo: A velocidade e a intensidade com que os seres humanos vêm se apropriando dos recursos naturais modificaram as dinâmicas ambientais em todo planeta. O Antropoceno se baseia no pressuposto de que a humanidade recentemente se tornou um condicionante para transformações globais na circulação de água, no clima, na produtividade biológica, na biodiversidade, nos ciclos biogeoquímicos, nos padrões de sedimentação e na utilização global de terras e mares. Compreender o Antropoceno como regime de historicidade significa perceber que a aceleração no ritmo de apropriação dos recursos atinge a vida de todos e tem como resultado uma nova forma de conceber o tempo. Diferente da ideia progressiva e crescente estabelecida com a Revolução Industrial e Revolução Francesa, o tempo é agora materializado pelos limitados recursos naturais limitados do planeta Terra.

Palavras-chave: História Ambiental; Antropoceno; Regime de Historicidade.

Abstract: The speed and intensity with which human beings have been appropriating natural resources have changed environmental dynamics across the planet. The Anthropocene assumes that humanity has recently become determinant for global transformations in water circulation, climate, biological productivity, biodiversity, biogeochemical cycles, sedimentation patterns and the global use of land and seas. Understanding the Anthropocene as a regime of historicity means that the acceleration in the pace of consumption affects everyone's life and results in a new way of conceiving time. Unlike the progressive and growing idea established with the Industrial Revolution and the French Revolution, time is now materialized by the remaining limited natural resources of Planet Earth.

\footnotetext{
* Professor do Mestrado em Estudos Fronteiriços CPAN-UFMS e do Curso de História do Campus do Pantanal da Universidade Federal do Mato Grosso do Sul. Possui graduação, mestrado e doutorado em História pela Universidade Federal de Santa Catarina.

** Professor do Programa de Pós-Graduação em História, do Mestrado Profissional em Ensino de História e do curso de graduação em História da Universidade Federal do Ceará. Possui doutorado em História Cultural pela Universidade Federal de Santa Catarina e mestrado em História Social pela Universidade Federal do Ceará.
} 
Revista Brasileira de História \& Ciências Sociais - RBHCS

Vol. $12 \mathrm{~N}^{\circ} 23$, Janeiro - Junho de 2020

Keywords: Environmental History; Anthropocene; Historicity Regime.

\section{Introdução}

Pela primeira vez na história do planeta Terra uma das 1,2 milhões de espécies de seres vivos catalogados tem a capacidade modificar as dinâmicas bio-geo-físicas em todo o globo. A conjuntura se estabelece em função da capacidade de apropriação dos recursos naturais pelo Homo sapiens, que através da industrialização organizou regimes automatizados de conversão energética, inicialmente de biomassa, depois combustíveis fósseis, até energia nuclear e solar. Dessa forma, o impacto da vida humana no ambiente foi tão considerável que alterou a escala geológica, produzindo, assim, o Antropoceno.

Marc Bloch explica que a História é o estudo dos homens no tempo (2001). A História Ambiental tem como pressuposto que a experiência humana depende do ambiente. Portanto, compreende-se que a História como o estudo dos seres humanos no tempo e no espaço. Apesar do ambiente ter papel central nessa forma de se compreender a experiência humana, deve-se tomar cuidado com todo e qualquer determinismo nessa análise.

\section{História Ambiental e Regimes de Historicidade}

Para História Ambiental a vida humana condiciona e é condicionada pelo ambiente. Diferente da crença estabelecida a partir da Era Moderna de que o ambiente limita a experiência humana e que caberia ao homem, pelo uso da razão, libertar-se do jugo do ambiente. Desta forma, a apropriação dos recursos naturais tem um papel crucial na busca humana por liberdade. Apesar do surgimento de discussões acerca da questão ambiental passarem a ganhar volume e amadurecimento político somente a partir da década de 1970, a natureza (ou paisagem), sempre esteve presente nos estudos históricos do século XX, o que se pode perceber nas obras: "A Terra e seus Homens" de Marc Bloch e "Reno" de Lucien Febvre. Entretanto, a despeito dos elementos do espaço estarem presentes, eles eram evidenciados como um cenário, não como uma variável condicionada e condicionadora da experiência humana. Ainda, cabe considerar que atualmente a "pressão" que a crescente preocupação com os 
patrimônios naturais do planeta exerce sobre todo o campo científico, o que vem produzindo um renovado interesse sobre o meio ambiente (LOPES, 2010).

J. R. McNeill, um dos expoentes na História Ambiental estadunidense, assim como outros autores, aponta que nos anos setenta do século XX os movimentos ambientalistas ganham espaço na Europa e na América do Norte. A exemplo disso, o discípulo de Fernand Braudel, Emmanuel Le Roy Ladurie atenta para questões ambientais em dois dos seus livros mais importantes, tratando do clima, epidemias e terremotos no Sul da Espanha (MCNEILL, 2003, p.12). Acredita-se que as primeiras preocupações que tratam das questões ambientais, de forma semelhante às atuais, surgiram com o desenvolvimento da energia nuclear e sua utilização após Hiroshima e Nagasaki. Como afirma Alfred Crosby, “[...] as bombas de fusão da Guerra Fria relegaram as bombas de fissão para segunda classe” (CROSBY, 1995, p. 1185), o potencial destrutivo humano alcançou índices inimagináveis, testes e acidentes nucleares alteraram a forma com que os seres humanos concebiam sua perpetuação no planeta. A chegada à Lua também é evidenciada pelo autor como um acontecimento de grande importância, foi nesse momento que a humanidade pôde vislumbrar seu isolamento e o quanto o planeta é pequeno em relação ao sistema solar (CROSBY, 1995).

Tal reflexão investe diretamente contra a ideia de que os patrimônios naturais quando pensados e concebidos como recursos sejam infinitos, o que propõe novas abordagens e ponderações sobre o meio ambiente. Sobretudo nos anos 1970 há uma emergência da crescente ação ambientalista, endossada pela profunda ligação que a História Ambiental tem com o ambientalismo incorporando suas demandas, isto é, demandas da sociedade. Questões como conservação da natureza e controle da poluição foram somadas à equidade e justiça social. Contudo, apesar da agenda ambientalista amalgamar temas sociais e conservacionistas ela ainda hoje não é consenso (VEIGA, 2008).

Nesse sentido, a História Ambiental consegue tornar a disciplina histórica mais inclusiva, pois como aponta Donald Worster,

[...] a História Ambiental nasceu, portanto de um objetivo moral, tendo por trás fortes compromissos políticos, mas, à medida que amadureceu, transformou-se também num empreendimento acadêmico que não tinha simples ou única agenda moral ou política para promover. Seu objetivo principal se tornou aprofundar o nosso entendimento de como os seres humanos foram, através dos tempos, afetados pelo seu ambiente natural e, inversamente, como eles 
Revista Brasileira de História \& Ciências Sociais - RBHCS

Vol. $12 \mathrm{~N}^{\circ} 23$, Janeiro - Junho de 2020

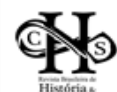

afetaram esse ambiente e com que resultados (WORSTER, 2003, p. 25).

Houve, portanto, uma rejeição da premissa convencional de que a experiência humana se desenvolveu sem restrições naturais, pois além de cenário o ambiente também é ator, ou seja, condicionado pelas interações humanas e condicionador das mesmas. Worster também abdica da ideia de que os humanos são uma espécie distinta 'supernatural' (WORSTER, 2003), apesar da espécie Homo sapiens ser a única dentre as cerca de três milhões de espécies catalogadas do planeta promotora do que se entende por cultura (como em oposição ao natural). Suas necessidades e aspirações devem ser pautadas pelos princípios da sustentabilidade e as consequências ecológicas de seus feitos passados não podem ser ignoradas.

A História Ambiental nasce com o objetivo de produzir uma investigação aberta e não reducionista das interações entre sistemas sociais e sistemas naturais, pautada em uma constante inter-relação, ou seja, uma “via de mão dupla”, que caminha sempre para longe dos determinismos do começo do Século XX (PÁDUA, 2010). Desta forma, a História Ambiental, até a produção do conceito de Antropoceno, advogou sobre a necessidade de debate acerca do retorno dos condicionantes ambientais na vida humana, buscando, assim, relativizar a "supra naturalidade" (WORSTER, 2003) que o Homo sapiens, conscientemente ou não, inseria-se. Com as bases conceituais do Antropoceno tal arranjo precisa ser revisto.

Entretanto, a supervalorização da ação humana nos estudos ambientais produzida pelo conceito do Antropoceno corre o risco de produzir um "curto-circuito" teórico. Pois aquela espécie, o Homo sapiens, que outrora era vista como herdeira do mundo e responsável pela dominação da natureza, ao longo do século XX passou a ser observada pelos cientistas ambientais como mais uma das espécies que habitam o planeta. Com a nova percepção, o papel da espécie humana na dinâmica planetária mudou novamente, pautando novos desafios na escrita da história ambiental. $\mathrm{O}$ Antropoceno produziu uma concentração de atribuições à espécie humana, que não necessariamente se traduz em centralidade nas dinâmicas ecológicas em todo o globo (LOPES, 2015).

Nesse sentido, torna-se necessário entender como a apreensão da temporalidade é produzida no contexto da vida humana. Na abordagem de François Hartog, os regimes de historicidade são as compreensões de diferentes ordens e formas de percepção do tempo. Em Regimes de Historicidade, demonstra que tais maneiras 
de conceber o tempo variam em lugares e épocas. Apesar de o historiador produzir esse conceito para endossar a ideia de um presentismo fortemente influenciado pela aceleração do tempo, o conceito do regime de historicidade pode ser utilizado de uma forma mais ampla para engrenar concepções de passado, presente e futuro (HARTOG, 2015, p.11).

Destaca-se ainda, que o conceito de regime de historicidade relaciona-se com o tempo exógeno e objetivo, um tempo da astronomia, entretanto o conceito de Hartog não se baseia em uma realidade dada, mas, especialmente, nas percepções produzidas pelas sociedades nas mais diversas culturas para compreender a passagem do tempo. Este termo é uma ferramenta para compreender as definições de tempo e suas consequências sociais (HARTOG, 2015).

Partindo de diversas experiências de tempo, o regime de historicidade se pretenderia uma ferramenta heurística, ajudando a melhor apreender, não o tempo, todos os tempos ou a totalidade do tempo, mas principalmente momentos de crise no tempo, aqui e lá, quando vem justamente perder sua evidência as articulações do passado, do presente e do futuro (HARTOG, 2015, p.37).

No intuito de conceituar o atual regime de historicidade que o mundo globalizado compartilha, François Hartog avalia as questões ambientais, mesmo que de forma superficial. Para o autor, no atual regime de historicidade, a noção de progresso que corrobora com a ideia de uma aceleração acumulativa, benéfica e civilizacional já cai por terra, à medida que se caracteriza por uma forma violenta de apropriação de recursos naturais, produtora de degradações ambientais capazes de colocar em risco a vida humana (HARTOG, 2015, p.239). O historiador destaca que a degradação ambiental perseguiu uma incessante patrimonialização do meio ambiente. Como recurso para os tempos de crise, que busca proteger o presente e preservar o futuro (HARTOG, 2015, p. 240).

A percepção do tempo produzida no Iluminismo, de um tempo progressivo e benéfico que conforme passava alargava o conhecimento da humanidade sobre si mesma e sobre o planeta foi solapada por um cronômetro regressivo, que vai caminhando para o seu fim, enquanto os recursos naturais vão sendo consumidos. Nas palavras de Hartog:

Esse futuro não é mais um horizonte luminoso ao qual caminhamos, mas uma linha de sombra que colocamos em movimento em nossa direção, enquanto parecemos patinar no campo do presente e ruminar um passado que não passa (HARTOG, 2015, p.245). 
$\mathrm{Na}$ visão de Hartog, o atual regime de historicidade, definido como presenteísmo, é marcado pela experiência de um presente contínuo, em que a tirania do instante define a vida, e por um horizonte que não passa da projeção de um agora sem fim. O passado é compreendido de forma paradoxal, ora com nostalgia e uma busca por restauração, ora com desprezo como o lugar do atraso que não fornece referenciais para a vida no presente. $O$ futuro não oferece mais garantias para uma vida que não consegue ser mais pautada na ideia de progresso (HARTOG, 2015). Assim, o presenteísmo é esse momento de crise no tempo, em que passado e futuro não servem mais como referenciais para a vida.

Para compreender como as apropriações do tempo são produzidas, Hartog utiliza os conceitos elaborados por Reinhart Koselleck de campo de experiência e horizonte de expectativa. Para Koselleck, "todas as histórias foram construídas pelas experiências vividas e pelas expectativas das pessoas que atuam ou que sofrem. Com isso, ainda nada dissemos sobre uma história concreta - passada, presente e futura" (KOSELLECK, 2006, p.306). A preocupação do historiador neste caso, está em evidenciar a posição fundante de experiência e expectativa para ação humana, sem, necessariamente, defender o caráter estruturante das categorias. A fundação faz parte da estrutura, entretanto a estrutura dessas histórias concretas vai além do que as expectativas e experiências individuais podem oferecer.

Um dos pontos centrais para o uso de tais categorias está na interconexão temporal produzida pelo seu emprego, uma vez que "a experiência é o passado atual, aquele no qual acontecimentos podem ser lembrados. Na experiência se fundem tanto a elaboração racional quanto as formas inconscientes de comportamento, que não estão mais, ou que não precisam mais estar presentes no conhecimento" (KOSELLECK, 2006, p.309). Algo semelhante ocorre com a expectativa, pois é entendida como a materialização do futuro no presente, assim “esperança e medo, desejo e vontade, a inquietude, mas também a análise racional, a visão receptiva ou a curiosidade fazem parte da expectativa e a constituem" (KOSELLECK, 2006, p.309). Ao relacionar o horizonte como uma linha por traz da qual se abre o futuro, Koselleck tem como base um futuro que referencia o instante da tomada de decisão. Neste caso, o futuro prognóstico é possibilidade referenciada pelo contexto espaço temporal presente e passado que o indivíduo se insere. 
Entretanto, a aglutinação de modelos de ritmos diferenciados - como por exemplo, o progresso tecnológico e o tempo cíclico do mundo natural - não foi devidamente analisada por Koselleck ao tratar das categorias espaço de experiência e horizonte de expectativa. A relação entre os modelos foi examinada no livro Estratos do Tempo: estudos sobre História, em que se vale da metáfora geológica para dar conta das diversas durações que atuam simultaneamente sobre o presente (KOSELLECK, 2014).

A metáfora geológica serve para esclarecer um dos pressupostos básicos de Koselleck. Nas palavras do historiador, "uma das teses que constituem meu ponto partida é a de que os tempos históricos podem ser distinguidos claramente dos tempos naturais, embora ambos se influenciem reciprocamente” (KOSELLECK, 2014, p. 10). Desta forma, livre das interpretações produzidas sobre os ritmos e passagem do tempo, há uma materialidade temporal ou tempo astronômico que transcorre independente da percepção dos seres humanos. Sobre a definição dos "estratos do tempo":

Situo-me no campo das metáforas: a expressão "estratos do tempo" remete a formações geológicas que remontam a tempos e profundidades diferentes, que se transformam e se diferenciam umas das outras em velocidades distintas no decurso da chamada história geológica. (...) sua transposição para a história humana, política ou social permite separa analiticamente diversos planos temporais em que as pessoas se movimentam, os acontecimentos se desenrolam e os pressupostos de duração mais longa são investigados (KOSELLECK, 2014, p. 19).

A ideia central do modelo explicativo de Koselleck está em solapar a oposição entre o linear e o circular na produção dos modelos históricos de interpretação do tempo e, assim, destacar as pluralidades e inter-relações destes modelos.

A analogia ao tempo geológico é profícua na análise deste trabalho também para compreender como um estrato mais profundo pode influenciar os demais. Apesar de Koselleck não fazer diferenciação sobre as diversas camadas que compõem os estratos do tempo, no começo de seu trabalho destaca que há um tempo natural, que é anterior e distinto do tempo histórico. A premissa do presente artigo é que esse tempo distinto não existe mais. $\mathrm{O}$ Antropoceno assinala a reentrada definitiva do mundo natural no tempo da vida humana.

\section{Antropoceno}


Revolução Agrícola de 11.000 a.C. e a Revolução Industrial devem ser entendidas como os processos mais significativos que possibilitaram à humanidade acelerar sua dinâmica de apropriação dos recursos naturais. Diversas foram as consequências da Revolução Industrial: a busca pelo uso cada vez maior da ciência e tecnologia no processo produtivo; a constante liberação da força de tração muscular humana; a especialização na exploração do trabalho humano.

No campo da História Ambiental, as discussões têm apontado para debates que buscam os antecedentes da Revolução Industrial. Para Robert Marks, a Revolução Industrial, marca uma transição entre um Antigo Regime Biológico, baseado no fluxo de energia solar, para um fluxo de energia baseado em outras reações químicas, em especial, dos combustíveis fósseis (MARKS, 2012, p. 61). Porém, durante o período do início da modernidade, uma série de elementos fez com que o Antigo Regime Biológico entrasse em questionamento: o aumento demográfico na Europa; a introdução, disseminação e mercantilização de plantas, animais e fungos do Novo mundo; e o próprio imperialismo em sua dimensão global.

No entanto, Marks entende que durante o século XVIII havia indícios que vários lugares no mundo atingiram os limites ecológicos do Antigo Regime Biológico, especialmente pela falta de recursos e devido os limites do crescimento terem chegado a um novo estágio (MARKS, 2012, p. 64). O autor, utilizando do aparato da História Global para sua análise, entende que, ao mesmo tempo, existiu uma crise ecológica na China e na Europa, que tiveram como resultado processos distintos. Marks considera que a diferença da Inglaterra para a China foi que os primeiros conseguiram localizar uma fonte de energia que faria com que estes não dependessem mais da energia de baixa entropia. Mais do que isso, os combustíveis fósseis foram a chave para o desenvolvimento e difusão da industrialização, assim, a industrialização resulta de uma nova relação enérgica das sociedades humanas (MARKS, 2012, p. 66). Marks observa que sem a expansão de outros recursos genéticos (o açúcar, para a alimentação humana, por exemplo) e sem as condições políticas (o colonialismo e a acumulação de capital que propicia), a própria Revolução Industrial teria sido um fracasso.

O historiador ambiental John McNeill, no livro Something under the sun: an environmental history of the Twenteth-Century World (2001), produz um apanhado histórico dos regimes de apropriação de energia realizados pelos seres humanos e identifica o século XX como o momento que concentrou a transformação das dinâmicas energéticas do planeta. Apesar das transformações remontarem os quatro 
bilhões de anos, desde sua formação, foi entre os últimos dois séculos que uma espécie dentre as milhões que habitam a crosta terrestre conseguiu transformar as dinâmicas biogeofísicas com significativa intensidade e rapidez. McNeill se vale dos indicadores econômicos para apontar o aumento da atividade produtiva: segundo ele, por volta de 1820 o Produto Interno Bruto (PIB) mundial havia alcançado 695 bilhões de dólares, com o incremento da navegação a vapor e a industrialização esse número chegou a 1,98 trilhões de dólares em 1900 (MCNEILL, 2001, p. 52). Este período de maior crescimento econômico visto até então foi logo eclipsado na primeira metade do século $\mathrm{XX}$, mesmo com o surgimento das duas grandes guerras mundiais. No início da década de 1950 o PIB global já tinha chegado a 5,37 trilhões de dólares, uma economia global quase 10 vezes maior que a de 1820. Na última década do século XX, o PIB global alcançou a marca de 28 trilhões de dólares, sendo que o período de 1950 a 1973 foi o de maior crescimento já visto até então (MCNEILL, 2001, p. 53).

Outra evidência trazida pelo historiador para comprovar as transformações produzidas pelos seres humanos ao longo dos últimos dois séculos é o crescimento demográfico. Apesar dos indicadores demográficos serem mais confiáveis que os econômicos, é preciso ter consciência de que para algumas partes do globo eles se apresentam como estimativas. McNeill defende que as duas grandes revoluções que possibilitaram o crescimento populacional foram a agrícola e a industrial. Há 11.000 anos, com o início do desenvolvimento da agricultura, o crescimento populacional poderia ser de 10 ou 1000 vezes maior que anteriormente, contudo esse crescimento não pode ser ingenuamente direcionado ao infinito, visto que os mais diversos grupos agrícolas sempre lidavam com as limitações impostas pelo ambiente (MCNEILL, 2001, p. 57). O primeiro bilhão de indivíduos foi alcançado por volta de 1820, o segundo bilhão teria sido alcançado em 1930, o terceiro em 1960 e a partir de 1975. A cada 15 anos um novo bilhão de indivíduos estaria compartilhando os recursos no planeta (MCNEILL, 2001, p. 60).

Antes da Revolução Industrial, os seres humanos tinham a sua disposição sua força muscular e dos animais domesticados; a energia ineficazmente coletada da água e vento; e o calor, mas não a energia, produzida pela combustão da biomassa. A Revolução Industrial transformou radicalmente a história do planeta, ao produzir motores que convertem em energia mecânica a energia acumulada na biomassa e nos combustíveis fósseis (MCNEILL, 2001, p. 63). Na Terra, a energia é retida por um equilíbrio impreciso: o que chega como energia solar é equivalente ao que é dissipado 
no espaço como calor. Energia não pode ser criada ou destruída. Dessa forma, toda energia é nuclear, pois vem da reação de fusão nuclear no sol.

São diversos os processos que convertem energia, cada conversão implica uma "perda” energética que normalmente é dissipada através do calor. O corpo humano, por exemplo, é $18 \%$ eficiente na conversão da energia consumida através dos alimentos. O que aconteceu na Revolução Industrial foi que pela primeira vez os seres humanos se tornaram capazes de converter energia em um curto espaço de tempo e usar essa conversão a seu favor (MCNEILL, 2001, p. 65). A agricultura e a domesticação de animais criaram um excedente energético que poderia ser aplicado de forma que a estruturação dos sistemas políticos sempre tivesse intimamente ligada ao regime de direcionamento energético de cada sociedade. McNeill destaca que antes da Revolução Industrial a forma mais eficiente de armazenamento de energia somática era a escravidão, justamente pelo fato de determinados grupos sociais se aproveitarem e direcionarem a maneira como outro grupo, os escravos, convertem seu consumo energético em trabalho (MCNEILL, 2001, p. 67).

Entretanto, a conversão de combustíveis fósseis em energia mecânica nos primeiros momentos da Revolução Industrial produzia uma perda de $99 \%$ da energia transformada. Os primeiros motores produzidos demoraram a chegar a $5 \%$ de eficiência, mas quando chegaram tinham capacidade de 20 quilowatts de potência, o equivalente ao trabalho de 200 homens (MCNEILL, 2001, p. 67). No começo do século $\mathrm{XX}$, a custo, os engenheiros já haviam aprendido a controlar vapor de alta pressão, o que fazia os motores serem 30 vezes mais potentes que em 1800. Esse processo produziu uma reação em cadeia que permitiu o transporte de carvão mineral em uma escala massiva, providenciando combustível para motores a vapor, o que transformou a navegação ao redor do globo.

A tecnologia de combustão interna usando óleo refinado também redefiniu os rumos do desenvolvimento. O período da Pax Britânica culminou com o auge no uso do carvão como combustível fóssil; com a troca do combustível base do processo industrial, uma nova potência emergia no cenário internacional. Por volta de 1880, engenheiros alemães conseguiram aprimorar os motores de combustão ao óleo, que ofereciam menos perda energética, consecutivamente, mais potência e pesavam menos (MCNEILL, 2001, p. 68). A Segunda Revolução Industrial, conhecida como a revolução química, colocaria a Alemanha na disputa por recursos naturais e mercados consumidores ao redor do globo. A Pax Britânica encontrou seu declínio no começo do 
XX com a ascensão de uma Alemanha recentemente unificada e que se movia rapidamente pela força de seus motores.

Apesar da utilização de novas fontes de energia para intensificação do processo produtivo, o carvão mineral foi a fonte energética mais usada até o final do século XX. Nos primeiros anos da Revolução Industrial, por volta de 1800, a produção mundial de carvão mineral era pequena, cerca de 10 milhões de metros cúbicos, comparado com a estimativa de consumo de biomassa de 1 bilhão de metros cúbicos. Na virada do século XIX para o XX o consumo de biomassa tinha aumentado cerca de 40\%, chegando a aproximadamente 1,4 bilhões de $\mathrm{m}^{3}$, e o aumento do consumo de carvão mineral cresceu exponencialmente, chegando a 1 bilhão de $\mathrm{m}^{3}$.

Por volta de 1990, segundo McNeill, o consumo de biomassa havia aumentado para 1,8 bilhões de $\mathrm{m}^{3}$, enquanto a produção de carvão mineral quintuplicou para 5 bilhões de $\mathrm{m}^{3}$ e se mantinha superior ao consumo de petróleo, que era incipiente no começo do século, e que chegava a 3 bilhões de $\mathrm{m}^{3}$ (MCNEILL, 2001, p. 72). Nenhum outro século pode ser comparado com o XX em termos de crescimento do uso e quanto à utilização de energia: "nós provavelmente consumimos mais energia desde 1990 que em toda história da humanidade antes de 1900” (MCNEILL, 2001, p. 73).

A intensificação do consumo de energia veio com dois custos principais. $\mathrm{O}$ primeiro deles é a poluição produzida pelo consumo de combustíveis fósseis, da mesma forma que a queima de biomassa; combustíveis fósseis tem mais poder combustivo e geram mais energia, mas também produzem mais poluição. O segundo custo pode ser percebido no aumento desigual de riqueza e poder entre diferentes partes do mundo. As tecnologias para intensificação da apropriação energética e as estruturas políticas para constituir o Estado defensor da industrialização foram produzidas primeiro na América do Norte e na Europa Ocidental, enquanto que outras partes do mundo continuavam dependentes da biomassa como fonte de calor e da energia somática de seres humanos e animais domesticados até meados do Século XX (MCNEILL, 2001, p. 75). Segundo McNeill, tal conjuntura produziu um desequilíbrio no Sistema Político Internacional que reflete nos padrões individuais de consumo. Na década de 1990, um estadunidense padrão gastava de 100 a 50 vezes mais energia por dia que um habitante de Bangladesh (MCNEILL, 2001, p. 76).

Nos últimos duzentos anos, a capacidade humana de apropriação dos assim denominados recursos naturais cresceu exponencialmente - e, por isso, as dinâmicas biogeofísicas do planeta também foram alteradas, o que corrobora, a nosso ver, a teoria 
Revista Brasileira de História \& Ciências Sociais - RBHCS

Vol. $12 \mathrm{~N}^{\circ} 23$, Janeiro - Junho de 2020

de que os seres humanos estariam produzindo uma nova era geológica, o Antropoceno (CRUTZEN, STEFFEN, 2003). A possibilidade da conversão energética alcançada na Revolução Industrial ofereceu aos seres humanos uma possibilidade inalcançada até hoje por nenhuma outra espécie, a de produzir meios de transformar as dinâmicas naturais do planeta (CRUTZEN, STEFFEN, 2003).

O geólogo alemão Reinhold Leinfelder defende o Antropoceno como uma hipótese científica que se baseia no pressuposto de que a humanidade recentemente se tornou um condicionante para transformações globais na circulação de água, no clima, na produtividade biológica, na biodiversidade, nos ciclos biogeoquímicos, nos padrões de sedimentação e na utilização global de terras e mares (LEINFELDER, 2013).

Leinfelder explica que tal hipótese tem implicações de grande alcance. Os dados que dão suporte ao início de uma nova era mostram que aproximadamente $77 \%$ da superfície terrestre já foi, ou tem sido, de alguma forma utilizada pelos humanos. Dessa forma, o mundo não poderia mais ser caracterizado por biomas - conjuntos naturais de habitats -, mas, sim, “antromas" - paisagens culturais, tais como florestas manejadas, terras agrícolas, pastagens e áreas urbanas (LEINFELDER, 2013). A antropização das dinâmicas naturais da Terra teria começado há 12 mil anos com a Revolução Agrícola do Neolítico, mas só teria se constituído enquanto tal depois da utilização dos combustíveis fósseis na Revolução Industrial, que encontrou seu ponto de multiplicação com a "Grande Aceleração Industrial” depois da Segunda Guerra Mundial.

Essa Grande Aceleração oferece uma oportunidade para comparar a aceleração dos processos naturais às acelerações sociais, tais como o aumento no Produto Interno Bruto (PIB) global, a financeirização da economia, a barragem de rios, o uso de fertilizantes, a polinização das flores, o crescimento da população urbana, o consumo de papel, a dispersão dos restaurantes de fast food, ou as vendas de telefones celulares (LEINFELDER, 2013).

Seguindo as discussões sobre o Antropoceno, Kathryn Yusoff defende em $A$ Billion Black Anthropocenes or None (2018), que o acalorado debate que tem se produzido na última década é fruto da repentina exposição das comunidades liberais brancas dos países desenvolvidos às mudanças ambientais. Yusoff esclarece que nos últimos séculos, mudanças ambientais e transformações sociais foram a regra em países colonizados e explorados pelas potências capitalistas, na esteira do processo 
civilizatório grupos pretos, pardos e populações indígenas foram vulnerabilizados pelas forças coloniais (2018).

Para Yusoff, o conceito de Antropoceno está sendo aceito na academia pela sua capacidade de inocentar os grupos sociais que mais promoveram a exploração social e degradação ambiental. Desta forma, defende bilhões de Antropocenos ou nenhum, ou seja, que o conceito seja aplicado a contextos e grupos sociais específicos e que a geologia tome partido e defina o começo do Antropoceno a partir da migração forçada de africanos para compor força de trabalho na América.

Contudo, com o entendimento que os seres humanos têm transformado as dinâmicas bio-geo-físicas do planeta o lugar do Homo sapiens na narrativa da História Ambiental precisa ser revisto. Nesse caminho, a discussão proposta por Kathryn Yusoff (2018) aponta a necessidade de olhar para os grupos sociais em maior condição de vulnerabilidade nos mais diferentes contextos históricos e geográficos frente às mudanças climáticas.

A História Ambiental marcou a reentrada do mundo natural na historiografia. O descompasso entre História e natureza, segundo William Cronon, foi produzido na década de 1930, quando o materialismo histórico havia se transformado em ferramenta para lutar contra o determinismo geográfico. Na migração dos marxistas/materialistas para longe das ciências naturais, chegaram ao extremo do determinismo cultural, sua preocupação era que o determinismo natural acabasse com a liberdade humana. (CRONON, 1993).

A partir da década de 1970, com o surgimento do ambientalismo, gradativamente o lugar do meio ambiente foi sendo conquistado na narrativa histórica. Com o surgimento do Antropoceno torna-se necessário reavaliar o lugar do humano na escrita da história. Neste ponto, seguindo as considerações de Kathryn Yusoff (2018), defende-se uma narrativa que privilegie as populações mais vulneráveis.

Ailton Krenak explica que o Antropoceno precisa ser compreendido como resultado do projeto Universalista da era Moderna. Nesse projeto, há a submissão da natureza aos desígnios dos seres humanos, que também se desvinculam do mundo natural, ao acreditar numa pretensa superioridade humana sobre o resto da natureza.

Um sujeito que saia da Europa e descia numa praia tropical largava um rastro de morte por onde passava. O indivíduo não sabia que era uma peste ambulante, uma guerra bacteriológica em movimento, um fim de mundo; tampouco o sabiam as vítimas que eram contaminadas. Para os povos que receberam aquela visita e morreram o fim do mundo foi no século XVI. Não estou liberando a responsabilidade e a gravidade 
de toda a máquina que moveu as conquistas coloniais, estou chamando a atenção para o fato de que muitos eventos que aconteceram foram o desastre daquele tempo. Assim como nós estamos vivendo o desastre do nosso tempo, ao qual algumas seletas pessoas chamam de Antropoceno. A grande maioria está chamando de caos social, desgoverno geral, perda de qualidade no cotidiano, nas relações, e estamos todos jogados nesse abismo (KRENAK, 2019, p. 71-72).

Na lógica desenvolvida por Krenak o Antropoceno é o conceito que representa o fim da externalização da degradação ambiental. O projeto universalista da modernidade, que foi levado a cabo pelo capitalismo ao longo do último século, conseguiu envolver todo globo terrestre e, com isso, disseminou a racionalidade da natureza enquanto recurso para o desenvolvimento humano. Krenak destaca que a experiência do Antropoceno colocaria o indivíduo moderno pela primeira vez em contato com o vislumbre da extinção, uma experiência que, infelizmente já é comum, aos povos indígenas brasileiros (2019).

\section{Considerações (quase) finais}

A iminência do fim do mundo reintroduz a natureza no centro da vida humana, ao mesmo tempo que recoloca os seres humanos no mundo natural. O Antropoceno emerge como um conceito que materializa a ânsia por dominação do homem moderno, quando pela busca da dominação da natureza, passa a experimentar as consequências da crença em sua especialidade.

Desta forma, o Antropoceno assinala a reentrada definitiva do mundo natural na representação do tempo. As dinâmicas sociais da apropriação e partilha dos recursos naturais produziu um novo regime de historicidade em que o tempo é percebido como regressivo e o objeto usado para representar o transcorrer do tempo, é o planeta terra transformado e degradado pelo Homo Sapiens. Assim, a exclusão do tempo natural nos tempos humanos não faz mais sentido em um cenário em que a disputa pelos escassos recursos naturais dita as mais diversas formas de organização da vida. 
Revista Brasileira de História \& Ciências Sociais - RBHCS

Vol. $12 \mathrm{~N}^{\circ} 23$, Janeiro - Junho de 2020

\section{Referências bibliográficas}

BLOCH, M. Apologia da História ou O Ofício de Historiador. Rio de Janeiro: ed. Zahar, 2001.

CROSBY, A. W. The Past And Present Of Environmental History. American

Historical Review. v.100, no. 4, 1995. p. 1177-1189.

CRUTZEN, P.J.; STEFFEN, W. How long have we been in the Anthropocene era?

Climatic Change, n. 61, p. 251-257, 2003.

HARTOG, F. Regimes de historicidade: presentismo e experiências do tempo.

Belo Horizonte: Autêntica, 2015.

KOSELLECK, R. Estratos do Tempo. Estudos sobre história. Rio de Janeiro:

Contraponto/PUC-Rio, 2014.

KOSELLECK, R. Futuro passado: contribuição à semântica dos tempos históricos.

Rio de Janeiro: Contraponto/Editora PUCRio, 2006.

KRENAK, A. Ideias para adiar o fim do mundo. São Paulo: Cia das Letras, 2019.

LE GOFF, J. História e Memória. Campinas: Ed. da UNICAMP, 2003.

LEINFELDER, R. Assuming Responsibility for the Anthropocene: challenges and opportunities in education. In: TRISCHLER, H. Anthropocene: Envisioning the Future of the Age of Humans. RCC Perspectives, Munich, n. 3, p. 9-28, 2013. LOPES, A. R. S. Desastres socioambientais e memória no sul de Santa

Catarina (1974-2004). Tese (Doutorado) - Universidade Federal de Santa Catarina, Centro de Filosofia e Ciências Humanas, Programa de Pós-Graduação em História, Florianópolis, 2015.

LOPES, A. R. S. História Ambiental: Uma demanda contemporânea. Cadernos de Pesquisa do CDHIS (Online), v. 23, p. 483-496, 2010.

MARKS, R. The (modern) World since 1500. In: MCNEILL, John Robert; MAULDIN, Stewart. A companion to Global Environmental History. Nova York, Londres: Wiley- Blackwell, 2012, p. 57-78.

MCNEILL, J. R. Something New Under the Sun: an environmental history of the twentieth-century world. New York: W. W. Norton \& Co., 2003.

PADUA, J. A. As bases teóricas da história ambiental. Estudos Avançados, São Paulo, v. 24, n. 68. 2010, p. 81-101.

VEIGA, José Eli da. Desenvolvimento Sustentável: o desafio do século XXI. Rio de Janeiro: Garamond, 2008. 
Revista Brasileira de História \& Ciências Sociais - RBHCS

Vol. $12 \mathrm{~N}^{\circ} 23$, Janeiro - Junho de 2020

WORSTER, D. Transformações da terra: para uma perspectiva agroecológica na História. Ambiente \& Sociedade. v. V, n. 2, ago-dez. 2002. v. VI, n. 1, jan-jul. 2003.

YUSOFF, K. A Billion Black Anthropocenes or None. University of Minnesota, 2018.

Recebido em Março de 2020

Aprovado em Junho de 2020 